\title{
Stability indicating RP-UPLC method for simultaneous quantification of bempedoic acid and ezetimibe in bulk and pharmaceutical formulations
}

\author{
Uma Sai Teja Yarra and Sowjanya Gummadi *i
}

\begin{abstract}
Background: Bempedoic acid and Ezetimibe acid are used in combination for treatment of hypercholesterolemia. The current work was undertaken to develop a simple and rapid stability-indicating RP-UPLC method for the simultaneous estimation of Bempedoic acid and Ezetimibe in tablets as no such method was available. The chromatographic separation was performed with Waters Acquity $C_{18}[50 \times 2.1 \mathrm{~mm}, 1.7 \mu]$ column using methanol: acetonitrile: water [50: 30: 20, by volume] as mobile phase pumped at a flow rate $0.5 \mathrm{~mL} / \mathrm{min}$. The separated analytes were detected at $260 \mathrm{~nm}$ using UV detector.

Results: The separation of Bempedoic acid (BA) and Ezetimibe (EZ) was done at a retention time of 1.827 min. and $3.577 \mathrm{~min}$. respectively. The validation and stability studies of the present method were carried out according to the $\mathrm{ICH}$ guidelines. The linearity of the proposed method was in the range of $30-130 \mu \mathrm{g} / \mathrm{mL}$ and $5-50 \mu \mathrm{g} / \mathrm{mL}$ for Bempedoic acid and Ezetimibe respectively. Limit of detection (LOD) and limit of quantification (LOQ) were found to be $0.1216 \mu \mathrm{g} / \mathrm{mL}$ and $0.3685 \mu \mathrm{g} / \mathrm{mL}$ for Bempedoic acid and $0.1189 \mu \mathrm{g} / \mathrm{mL}$ and $0.3602 \mu \mathrm{g} / \mathrm{mL}$ for Ezetimibe respectively. The recovery of the method was found to be in the range of $99.89-100.31 \%$ for Bempedoic acid and $98.14-99.94 \%$ for Ezetimibe while the \% RSD for both drugs in the precision and robustness study was less than 2.0. The drugs did not show any major degradants in the exposed conditions.
\end{abstract}

Conclusion: The developed method was found to be simple, sensitive, accurate, precise, robust, rapid and yet stability indicating. The method can be adopted for simultaneous estimation of Bempedoic acid and Ezetimibe in the pharmaceutical formulation.

Keywords: UPLC, Bempedoic acid, Ezetimibe, ICH guidelines, Validation, Stability

\section{Background}

High LDL cholesterol (LDL-C) levels represent an important risk factor for cardiovascular diseases, which can be due to genetic mutations or lifestyle factors, hypercholesterolemia can substantially reduce life quality and increase the risk of cardiovascular disease mortality.

\footnotetext{
*Correspondence: tatinenijishnu@gmail.com

Department of Pharmaceutical Analysis, GITAM Institute of Pharmacy,

GITAM (Deemed To Be University), Visakhapatnam, Andhra Pradesh
}

530045, India
Bempedoic acid (Fig. 1a) and Ezetimibe (Fig. 1b) acid are used in combination for treatment of hypercholesterolemia and ASCVD by reducing lipid parameters and attenuating hsCRP levels [1]. Ezetimibe is an azetidinone derivative, it prevents absorption of cholesterol by blocking the Niemann-Pick C1-like 1 (NPC1L1) protein on epithelial cells of gastrointestinal tract, and in hepatocytes. It also blocks aminopeptidase $\mathrm{N}$ and interfere with caveolin 1-annexin A2 complex which is in cholesterol trafficking. This decreases hepatic cholesterol and cuts the total cholesterol level in the blood [2]. Bempedoic 


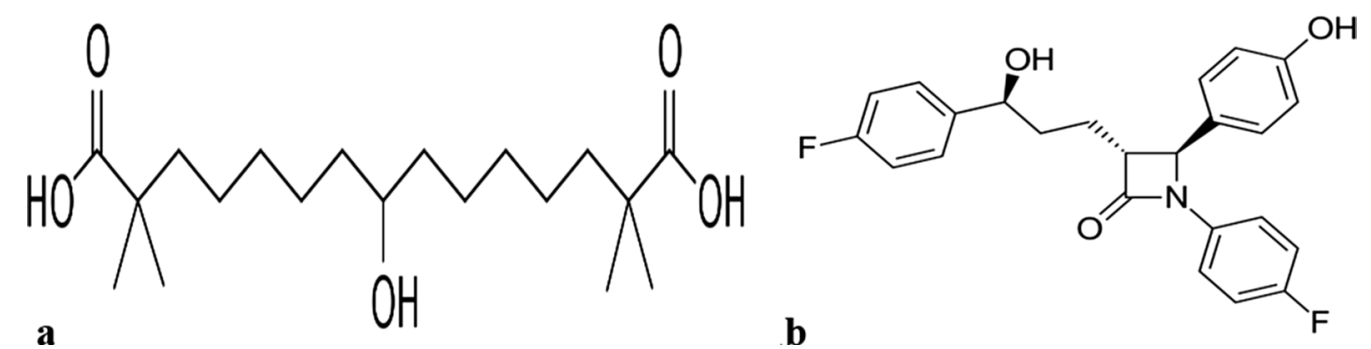

Fig. 1 a Chemical structure of Bempedoic acid. $\mathbf{b}$ Chemical structure of Ezetimibe

acid is a prodrug, the activated form inhibits adenosine triphosphate citrate lyase (ACL) inhibitor which is responsible for biosynthesis of cholesterol in liver [3].

A literature survey conveyed that, limited methods are available for simultaneous estimation of Bempedoic acid and Ezetimibe. A few articles reported spectrophotometric techniques for estimation of Ezetimibe alone and with other drugs [4-15]. Few HPLC methods were reported for the determination of Ezetimibe alone and in combination with other drugs [16-20]. One RP-HPLC method was reported for simultaneous estimation of Bempedoic acid Ezetimibe [21]. Few LC-MS methods were reported for determination of Ezetimibe alone and in combination with other drugs [22-25]. One LC-MS method was reported for estimation of Bempedoic acid in human plasma and urine [26]. To our knowledge, this is the first report of a stability indicating RP-UPLC method for simultaneous estimation of Bempedoic acid and Ezetimibbe in bulk and pharmaceutical formulations. The present work aims to develop stability indicating reverse-phase ultra-performance liquid chromatography (RP-UPLC) method for simultaneous estimation of Bempedoic acid and Ezetimibe in bulk and pharmaceutical formulations as per ICH guidelines.

\section{Methods}

Instrument

Acquity UPLC system equipped with quaternary pumps, Acquity TUV detector, and autosampler integrated.

\section{Pure samples}

Standard samples of Bempedoic acid $(99.5 \% \mathrm{w} / \mathrm{w})$ and Ezetimibe $(98 \% \mathrm{w} / \mathrm{w})$ were procured from Madras Pharmaceuticals, Chennai.

\section{Formulation}

Marketed formulation (tablets) of Bempedoic acid and Ezetimibe, NEXLIZET (Bempedoic acid $180 \mathrm{mg}$ and Ezetimibe $10 \mathrm{mg}$ ) was purchased online.

\section{Chemicals and reagents}

Acetonitrile, methanol, and water (HPLC grade) were procured from Merck. Sodium hydroxide, hydrochloric acid, hydrogen peroxide (AR grade) obtained from Rankem were utilised in the study.

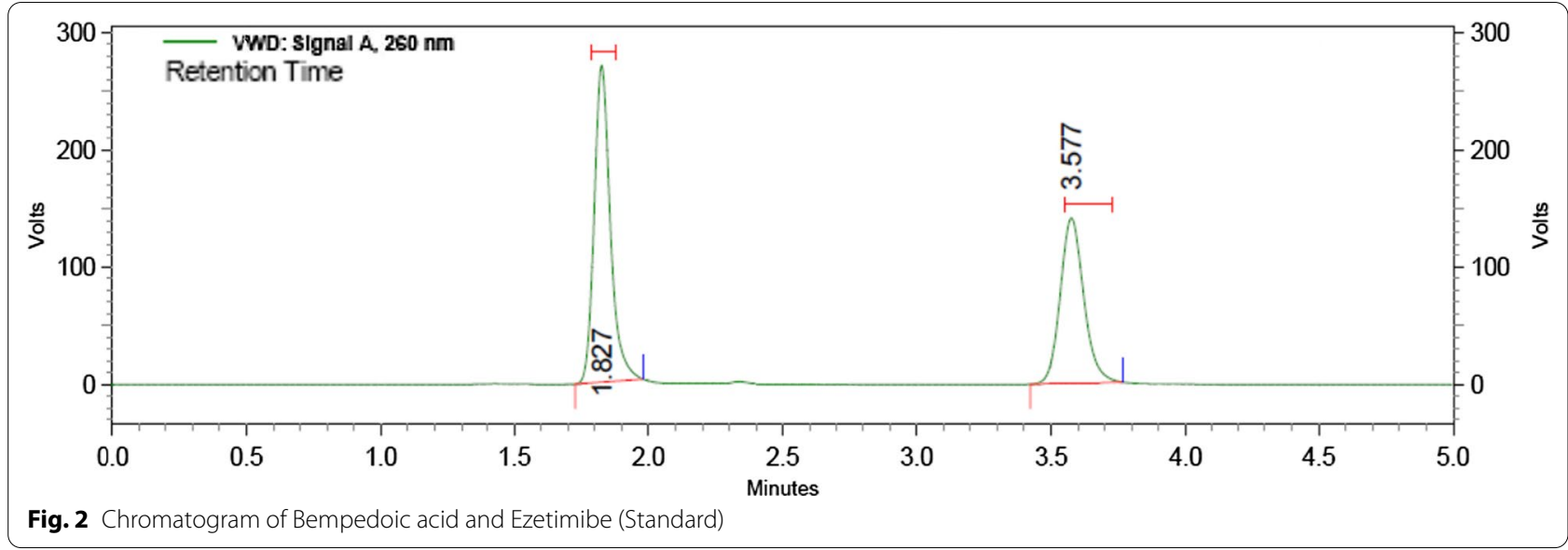




\section{Preparation of mobile phase/Diluent}

The mobile phase consists of methanol, acetonitrile and water in the ratio 50: 30: 20 , by volume. The solvent is filtered through $0.45 \mu$ membrane filter and sonicated before use.

\section{Preparation of stock and standard solutions}

Stock solutions of Bempedoic acid and Ezetimibe were prepared by dissolving $180 \mathrm{mg}$ of Bempedoic acid and $10 \mathrm{mg}$ of Ezetimibe in about $70 \mathrm{~mL}$ diluent, sonicated and further made up to volume in a $200 \mathrm{~mL}$ volumetric flask with the diluent. Pipetted $1 \mathrm{~mL}$ of the above solution and transferred into a $10 \mathrm{~mL}$ volumetric flask and made up to volume with diluent (standard solution). The stock solution was diluted as per requirement.

\section{Preparation of sample solution}

Twenty tablets (NEXLIZET) were weighed and crushed. Quantity of powder equivalent to $180 \mathrm{mg}$ of Bempedoic acid and $10 \mathrm{mg}$ of Ezetimibe was taken in a $200 \mathrm{~mL}$ volumetric flask, $70 \mathrm{~mL}$ of diluent was added, sonicated it for $30 \mathrm{~min}$ with intermittent shaking and the volume was made up with diluent. This solution was filtered through a $0.45 \mu \mathrm{m}$ membrane filter and further diluted.

\section{Determination of working wavelength}

$10 \mu \mathrm{g} / \mathrm{mL}$ solutions of both the components were prepared separately and scanned in the UV wavelength region of $200 \mathrm{~nm}$ to $400 \mathrm{~nm}$. An overlaying spectrum obtained was used to determine the working wavelength (isoabsorptive point).

\section{Method development}

Various system suitability parameters were analysed to optimize chromatographic conditions to achieve symmetric peak shape and better resolution of drugs. Optimization of mobile phase was done by combining
Table 1 Optimized chromatographic conditions

\begin{tabular}{|c|c|}
\hline Parameter & Optimized condition \\
\hline Mobile phase & $\begin{array}{l}\text { Methanol: acetonitrile: } \\
\text { water ( } 50: 30: 20 \text {, by } \\
\text { volume) }\end{array}$ \\
\hline Column & $\begin{array}{l}\text { Waters Acquity } C_{18} \\
(50 \mathrm{~mm} \times 2.1 \mathrm{~mm} \mathrm{ID} \text {, } \\
1.8 \mu \mathrm{m})\end{array}$ \\
\hline Flow rate & $0.5 \mathrm{~mL} / \mathrm{min}$ \\
\hline Column temperature & $25 \pm 2^{\circ} \mathrm{C}$ \\
\hline Wavelength & 260.00 nm (UV Detector) \\
\hline Injection volume & $10 \mu \mathrm{L}$ \\
\hline Elution & Isocratic mode \\
\hline Run time & $5 \mathrm{~min}$ \\
\hline \multicolumn{2}{|l|}{ Retention time } \\
\hline Bempedoic acid & $1.827 \mathrm{~min}$ \\
\hline Ezetimibe & $3.577 \mathrm{~min}$ \\
\hline
\end{tabular}

various suitable solvents in different ratios and finalized that methanol: acetonitrile: water $(50: 30: 20 \%, \mathrm{v} / \mathrm{v})$ as mobile phase at a flow rate of $0.5 \mathrm{~mL} / \mathrm{min}$. gave the most symmetric and resolved peaks detected at $260 \mathrm{~nm}$. Optimized chromatogram is shown in Fig. 2 and chromatographic conditions are given in Table 1.

\section{Method validation}

The validation of the proposed method was carried out as per ICH Q2 (R1) guidelines [27] and the validation parameters include system suitability, linearity, precision, accuracy, robustness, and specificity.

\section{Linearity}

Linearity was determined by preparing aliquots at six different levels of calibration curve over the concentration range of $30-130 \mu \mathrm{g} / \mathrm{mL}$ for Bempedoic acid and $5-50 \mu \mathrm{g} / \mathrm{mL}$ for Ezetimibe. Solutions for calibration curve were prepared by serial dilutions of stock solution to obtain concentrations of 30, 50, 70, 90, 110, $130 \mu \mathrm{g} / \mathrm{mL}$ of Bempedoic acid and 5, 10, $20,30,40,50 \mu \mathrm{g} / \mathrm{mL}$ of Ezetimibe. The solutions were analysed in triplicate. The correlation coefficient with the regression equation was determined from the calibration curve.

Table 2 Linearity data

\begin{tabular}{|c|c|c|c|c|}
\hline \multirow[t]{2}{*}{ S. No } & \multicolumn{2}{|l|}{ Bempedoic acid } & \multicolumn{2}{|l|}{ Ezetimibe } \\
\hline & Concentration $(\mu \mathrm{g} / \mathrm{mL})$ & ${ }^{*}$ Area $\pm S D$ & Concentration $(\mu \mathrm{g} / \mathrm{mL})$ & ${ }^{*}$ Area $\pm S D$ \\
\hline 1 & 30 & $16,674,907 \pm 12,562$ & 5 & $13,022,190 \pm 7369$ \\
\hline 2 & 50 & $25,055,621 \pm 18,075$ & 10 & $16,194,209 \pm 10,207$ \\
\hline 3 & 70 & $36,009,142 \pm 20,674$ & 20 & $25,035,716 \pm 18,128$ \\
\hline 4 & 90 & $45,211,483 \pm 44,895$ & 30 & $33,633,340 \pm 24,323$ \\
\hline 5 & 110 & $53,519,670 \pm 34,322$ & 40 & $41,910,697 \pm 37,208$ \\
\hline 6 & 130 & $63,933,476 \pm 49,587$ & 50 & $49,953,204 \pm 48,521$ \\
\hline
\end{tabular}

*Mean of three determinations; SD $=$ Standard Deviation 

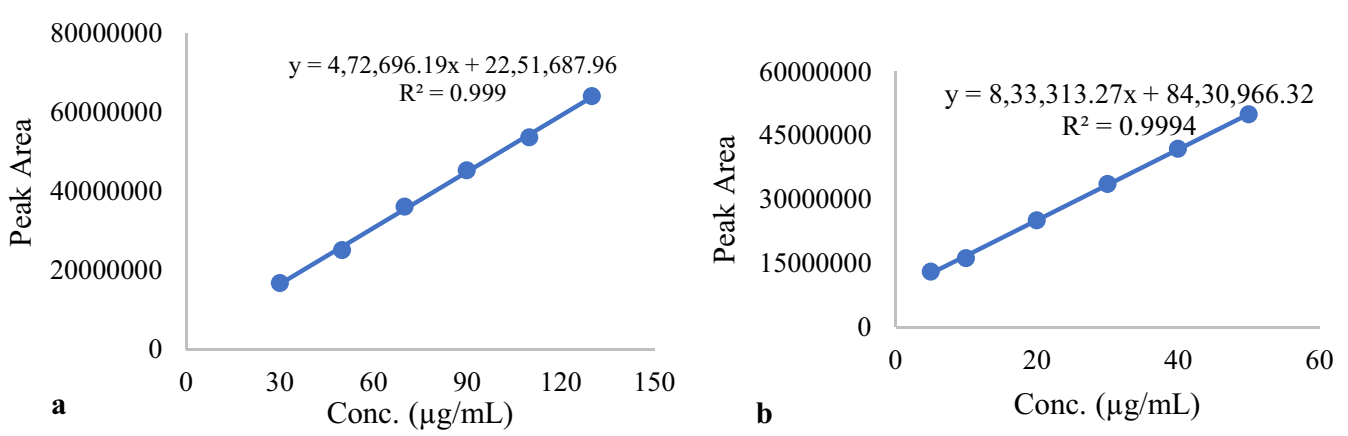

Fig. 3 a Calibration curve of Bempedoic acid. b Calibration curve of Ezetimibe

Table 3 Results for intraday precision

\begin{tabular}{|c|c|c|c|c|c|}
\hline \multicolumn{3}{|c|}{ Bempedoic acid } & \multicolumn{3}{|l|}{ Ezetimibe } \\
\hline $\begin{array}{l}\text { Conc. } \\
\text { taken } \\
(\mu \mathrm{g} / \\
\mathrm{mL})\end{array}$ & $\begin{array}{l}{ }^{*} \text { Assay }(\% \\
w / w) \pm S D\end{array}$ & $\begin{array}{l}\% \\
\text { RSD }\end{array}$ & $\begin{array}{l}\text { Concentration } \\
\text { taken }(\mu \mathrm{g} / \mathrm{mL})\end{array}$ & $\begin{array}{l}{ }^{*} \text { Assay (\% } \\
w / w) \pm S D\end{array}$ & $\begin{array}{l}\% \\
\text { RSD }\end{array}$ \\
\hline 90 & $100.59 \pm 0.1172$ & 0.12 & 5 & $99.64 \pm 0.3758$ & 0.38 \\
\hline
\end{tabular}

\section{Precision}

The precision of the method was studied in terms of intra-day precision and inter-day precision. Each phase of precision was investigated by six replicates of injections of sample solutions of Bempedoic acid $(90 \mu \mathrm{g} / \mathrm{mL})$ and Ezetimibe $(5 \mu \mathrm{g} / \mathrm{mL})$. Precision was expressed in terms of relative standard deviation.

\section{Accuracy}

Accuracy was expressed in terms of recovery. It was determined by spiking a known amount of standard Bempedoic acid and Ezetimibe to pre-analysed samples at three different levels such as 50\%, 100\%, and 150\%, and the percentage recovery was determined.

\section{Robustness}

The robustness of the method was determined by bringing deliberate variations in the method parameters such as flow rate, temperature and detection wavelength.

Limit of detection (LOD) and limit of quantification (LOQ) The limit of detection (LOD) and limit of quantitation (LOQ) were based on the standard deviation of the response and slope of the constructed calibration curve

Table 4 Results for interday precision

\begin{tabular}{|c|c|c|c|c|c|c|}
\hline \multirow[t]{2}{*}{ Day } & \multicolumn{3}{|l|}{ Bempedoic acid } & \multicolumn{3}{|l|}{ Ezetimibe } \\
\hline & $\begin{array}{l}\text { Conc. taken }(\mu \mathrm{g} / \\
\mathrm{mL})\end{array}$ & ${ }^{*}$ Assay $(\% \mathrm{w} / \mathrm{w}) \pm \mathrm{SD}$ & $\%$ RSD & $\begin{array}{l}\text { Conc. taken }(\mu \mathrm{g} / \\
\mathrm{mL})\end{array}$ & ${ }^{*}$ Assay $(\% \mathrm{w} / \mathrm{w}) \pm \mathrm{SD}$ & $\%$ RSD \\
\hline 1 & 90 & $100.52 \pm 0.1518$ & 0.15 & 5 & $99.58 \pm 0.2725$ & 0.27 \\
\hline 2 & & $100.78 \pm 0.1734$ & 0.17 & & $99.31 \pm 0.1988$ & 0.20 \\
\hline 3 & & $100.72 \pm 0.1353$ & 0.13 & & $99.40 \pm 0.3483$ & 0.35 \\
\hline
\end{tabular}

*Mean of six determinations; $S D=$ Standard Deviation; RSD = Relative Standard Deviation

Table 5 Results for accuracy

\begin{tabular}{|c|c|c|c|c|c|c|c|c|}
\hline \multirow[t]{2}{*}{ Level (\%) } & \multicolumn{2}{|c|}{ Tablet $(\mu \mathrm{g} / \mathrm{mL})$} & \multicolumn{2}{|c|}{ Standard $(\mu \mathrm{g} / \mathrm{mL})$} & \multicolumn{2}{|c|}{${ }^{*}$ Conc. Found $(\mu \mathrm{g} / \mathrm{mL})$} & \multicolumn{2}{|c|}{ *Recovery (\%) \pm SD } \\
\hline & $\overline{B A}$ & $\overline{E Z}$ & $\overline{B A}$ & $\mathrm{EZ}$ & $\overline{\mathrm{BA}}$ & $E Z$ & $\overline{B A}$ & $\mathrm{EZ}$ \\
\hline 50 & 50 & 10 & 25 & 5 & 75.07 & 14.99 & $100.31 \pm 0.2902$ & $99.94 \pm 0.3938$ \\
\hline 100 & & & 50 & 10 & 100.09 & 19.98 & $100.17 \pm 0.2419$ & $99.81 \pm 0.2114$ \\
\hline 150 & & & 75 & 15 & 124.58 & 24.87 & $99.89 \pm 0.1993$ & $98.14 \pm 0.1116$ \\
\hline
\end{tabular}

*Mean of three determinations; SD = Standard Deviation 
Table 6 Results for robustness study

\begin{tabular}{|c|c|c|c|c|c|c|c|c|c|}
\hline \multicolumn{2}{|l|}{ Chromatographic changes } & \multicolumn{2}{|l|}{ *Peak area } & \multicolumn{2}{|c|}{ Tailing Factor } & \multicolumn{2}{|c|}{$\begin{array}{l}\text { Theoretical } \\
\text { Plates }\end{array}$} & \multicolumn{2}{|c|}{${ }^{*}$ Assay $(\%$ w/w) $\pm S D, \%$ RSD } \\
\hline & & BA & EZ & BA & EZ & BA & EZ & BA & EZ \\
\hline \multirow[t]{3}{*}{ Flow rate \pm 0.1 (mL/min.) } & 0.4 & $45,118,072$ & $12,608,841$ & 1.184 & 1.407 & 3588 & 9450 & $100.59 \pm 0.1799,0.18$ & $99.91 \pm 0.3205,0.32$ \\
\hline & 0.5 & $44,965,324$ & $12,588,406$ & 1.172 & 1.166 & 3041 & 7911 & & \\
\hline & 0.6 & $45,051,231$ & $12,583,731$ & 1.144 & 1.123 & 2455 & 7299 & & \\
\hline \multirow[t]{3}{*}{ Temperature $\pm 5\left({ }^{\circ} \mathrm{C}\right)$} & 20 & $45,036,493$ & $12,584,203$ & 1.155 & 1.163 & 3481 & 9827 & $100.51 \pm 0.2184,0.22$ & $99.88 \pm 0.4116,0.41$ \\
\hline & 25 & $44,906,494$ & $12,580,784$ & 1.181 & 1.173 & 3112 & 8067 & & \\
\hline & 30 & $45,086,495$ & $12,612,046$ & 1.108 & 1.122 & 2484 & 6857 & & \\
\hline \multirow{3}{*}{ Detectionwavelength $\pm 2(\mathrm{~nm})$} & 258 & $44,934,914$ & $12,597,848$ & 1.153 & 1.141 & 3585 & 9708 & $100.53 \pm 0.1820,0.18$ & $99.60 \pm 0.3573,0.34$ \\
\hline & 260 & $45,040,389$ & $12,569,963$ & 1.158 & 1.174 & 3088 & 8102 & & \\
\hline & 262 & $45,085,863$ & $12,574,861$ & 1.134 & 1.128 & 2548 & 6989 & & \\
\hline
\end{tabular}

*Mean of three determinations; SD = Standard Deviation; RSD = Relative Standard Deviation

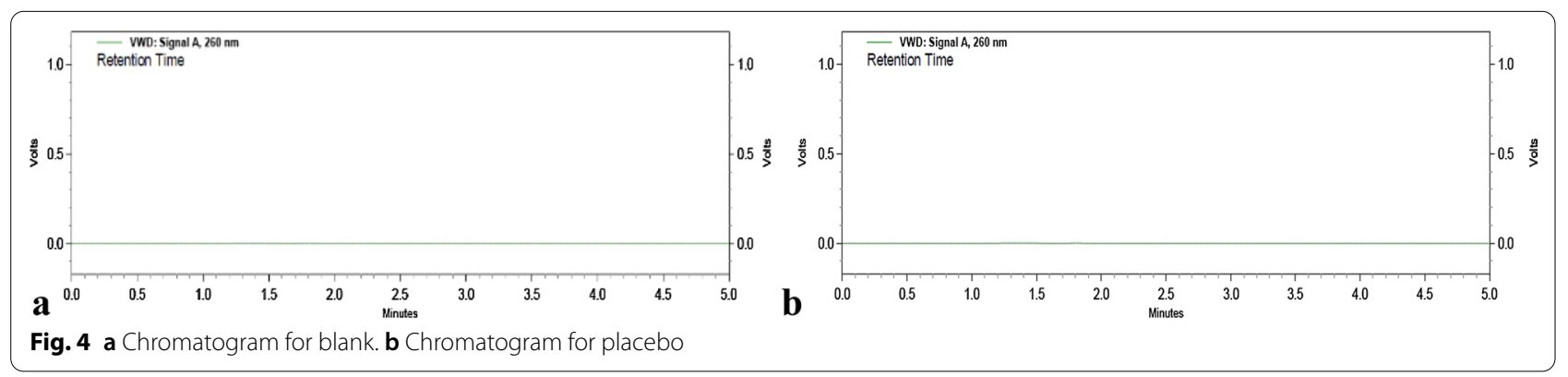

Table 7 Results for forced degradation studies

\begin{tabular}{|c|c|c|c|c|c|c|c|c|}
\hline \multirow[t]{2}{*}{ Degradation study } & \multicolumn{2}{|c|}{ *Assay (\%w/w) } & \multicolumn{2}{|c|}{ \% Degradation } & \multicolumn{2}{|c|}{ Tailing factor } & \multicolumn{2}{|c|}{ Theoretical plates } \\
\hline & $\mathrm{BA}$ & EZ & BA & EZ & BA & $\mathrm{EZ}$ & BA & EZ \\
\hline Control & 99.90 & 99.90 & - & - & 1.156 & 1.137 & 3679 & 7935 \\
\hline Acidic & 99.17 & 99.31 & 0.73 & 0.59 & 1.183 & 1.277 & 4129 & 8367 \\
\hline Alkaline & 99.26 & 99.42 & 0.64 & 0.48 & 1.294 & 1.248 & 3934 & 8753 \\
\hline Peroxide & 99.48 & 99.30 & 0.46 & 0.59 & 1.150 & 1.342 & 4352 & 8243 \\
\hline Thermal & 99.05 & 99.20 & 0.85 & 0.69 & 1.184 & 1.069 & 4253 & 7961 \\
\hline Photolytic & 99.62 & 99.67 & 0.28 & 0.23 & 1.215 & 1.283 & 4472 & 8452 \\
\hline
\end{tabular}

*Mean of three determinations; $\mathrm{BA}=$ Bempedoic acid; $\mathrm{EZ}=$ Ezetimibe

$(n=3)$. Sensitivity of the method was established with respect to LOD and LOQ for Ezetimibe and Bempedoic acid by slope method. Limit of detection and limit of quantitation was calculated using $\operatorname{LOD}=3.3 \sigma / \mathrm{S}$ and $\mathrm{LOQ}=10 \sigma / \mathrm{S}$.

Where, $\sigma$ is the standard deviation of the response and $\mathrm{S}$ is the slope of the standard curve.

\section{Specificity}

Specificity of the method was studied in the presence of excipients and degradants. Blank and placebo solutions were injected into the UPLC system and observed for any interfering peaks.

\section{Forced degradation studies}

Forced degradation studies were conducted to assess the stability-indicating property of the proposed method [28, 29]. The standard was exposed to various degradation conditions like acidic $\left(0.1 \mathrm{~N} \mathrm{HCl}, 60{ }^{\circ} \mathrm{C}, 1 \mathrm{~h}\right)$, alkaline $\left(0.1 \mathrm{~N} \mathrm{NaOH}, 60{ }^{\circ} \mathrm{C}, 1 \mathrm{~h}\right)$, peroxide $\left(20 \% \mathrm{H}_{2} \mathrm{O}_{2}\right)$, thermal $\left(105{ }^{\circ} \mathrm{C}, 6 \mathrm{~h}\right)$ and photolytic $(254 \mathrm{~nm}, 1$ day) stress. The exposed solutions were injected in replicates and the system suitability parameters were studied along the percentage degradations. 





Table 8 Results for assay

\begin{tabular}{lllll}
\hline $\begin{array}{l}\text { Marketed } \\
\text { formulation } \\
\text { (tablet) }\end{array}$ & Drug & $\begin{array}{l}\text { Label } \\
\text { claim } \\
(\mathbf{m g})\end{array}$ & $\begin{array}{l}\text { Amount } \\
\text { found } \\
(\mathbf{m g})\end{array}$ & $\begin{array}{r}{ }^{*} \text { Assay }(\% \\
\mathbf{w} / \mathbf{w}) \pm \text { SD }\end{array}$ \\
\hline NEXLIZET $^{\mathrm{TM}}$ & Bempedoic acid & 180 & 180.92 & 100.51 \\
& Ezetimibe & 10 & 9.91 & 99.11 \\
\hline
\end{tabular}

\section{Assay}

Assay of the marketed formulation (NEXLIZET, Bempedoic acid $180 \mathrm{mg}$ and Ezetimibe $10 \mathrm{mg}$ ) was performed by using the standard and sample solutions. $1 \mathrm{~mL}$ of the clear and filtered sample solution as discussed above was pipetted in to a $10 \mathrm{~mL}$ volumetric flask and made up to volume with diluent. The resulting solution was used to record the chromatogram.

\section{Results}

Several trials were performed using a combination of mobile phases some of which include phosphate buffer: acetonitrile (60:40), phosphate buffer, $\mathrm{pH}$ 4.0: methanol: triethylamine (45:35:15), methanol: water (70:30), acetonitrile: water (60:40) and methanol: acetonitrile: water (50:30:20). A variety of stationary phases such as Phenomenex, Zorbax and Waters Acquity columns of varying dimensions were used. All these combinations resulted in chromatographic peaks with different system suitability parameters from which the optimized condition has been chosen as methanol: acetonitrile: water (50:30:20) and a Waters Acquity $\mathrm{C}_{18}$ column $(50 \times 2.1 \mathrm{~mm} \mathrm{ID,} 1.8 \mu \mathrm{m})$ at a flow rate of $0.5 \mathrm{~mL} / \mathrm{min}$.

\section{Linearity}

Bempedoic acid and Ezetimibe obeyed linearity over the concentration range of $30-130 \mu \mathrm{g} / \mathrm{mL}$ and $5-50 \mu \mathrm{g} / \mathrm{mL}$ respectively. The regression equation and correlation coefficient was found to be $y=472,696.19 x+2,251,687.96(0.999)$ for Bempedoic acid and $y=833,313.27 x+8,430,966.32$ (0.9994) for Ezetimibe. Linearity data of Bempedoic acid and Ezetimibe is listed in Table 2. Calibration curves for Bempedoic acid and Ezetimibe are provided in Fig. $3 a$ and b.

\section{Precision}

For intraday precision \% RSD was calculated and it was $0.12 \%$ for Bempedoic acid and $0.38 \%$ for Ezetimibe, while $\%$ RSD value for interday precision was obtained in the range of $0.13-0.17 \%$ for Bempedoic acid and $0.20 \%-$ $0.35 \%$ for ezetimibe. All the values of $\%$ RSD were within the limits indicating a precise method. Results of intraday and interday precision are given in Tables 3 and 4, respectively.

\section{Accuracy}

The accuracy of the proposed method was assessed at three levels. The \% recovery of Bempedoic acid was found to be in the range of $99.89 \%-100.31 \%$ and the $\%$ recovery of Ezetimibe was found to be in the range of $98.14 \%-99.94 \%$ indicating the method is accurate. The accuracy results are listed in Table 5 and the data for robustness is given in Table 6 .

\section{Limit of detection (LOD) and limit of quantification (LOQ)}

Limit of detection for Bempedoic acid and Ezetimibe was found to be $0.1216 \mu \mathrm{g} / \mathrm{mL}$ and $0.1189 \mu \mathrm{g} / \mathrm{mL}$ respectively. Limit of quantification for Bempedoic acid and Ezetimibe was found to be $0.3685 \mu \mathrm{g} / \mathrm{mL}$ and $0.3602 \mu \mathrm{g} /$ $\mathrm{mL}$ respectively.

\section{Specificity}

No peaks were found in the diluent or placebo chromatograms at the retention times of Bempedoic acid and Ezetimibe indicating the specificity of the method in the presence of excipients as given in Fig. $4 \mathrm{a}$ and $4 \mathrm{~b}$.

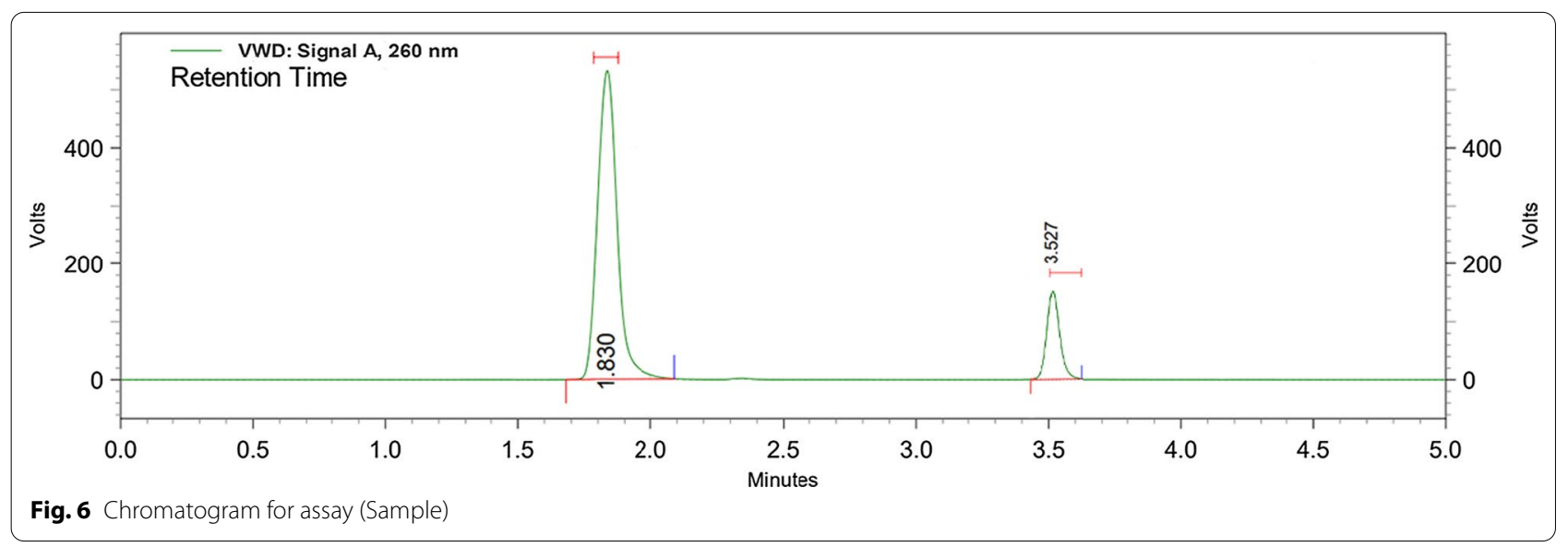




\section{Forced degradation studies}

Degradation studies has revealed that no major degradation of both Bempedoic acid and Ezetimibe occurred in the exposed acidic, alkaline, peroxide, thermal and photolytic conditions. The results regarding the forced degradation studies are provided in Table 7 and chromatograms are given in Fig. 5A-E.

\section{Assay}

The percentage assay of the sample was calculated by comparing the areas of standard and sample peaks and the results for assay of Bempedoic acid and Ezetimibe are listed in the Table 8. A representative chromatogram for assay is presented in Fig. 6 .

\section{Discussion}

An attempt has been made to develop a simple UPLC method for the simultaneous quantification of Bempedoic acid and Ezetimibe. The method optimization was started considering the solubility of the drugs in various aqueous and organic phases. A methanol: acetonitrile: water $(50: 30: 20 \%, v / v)$ system on a Waters Acquity $\mathrm{C}_{18}$ $(50 \mathrm{~mm} \times 2.1 \mathrm{~mm}$ ID, $1.8 \mu \mathrm{m})$ column gave the best possible chromatographic peaks. Short and small particle size columns enable faster retention and well resolved peaks within a short run time $(<5 \mathrm{~min}$.). The retention of both the drugs was found to be less than 4 min with a good resolution. The method validation and stability studies were carried out according to $\mathrm{ICH}$ guidelines. Validation parameters like precision and accuracy were within acceptable limits, indicating that the method is precise and accurate. LOD and LOQ results were less than $0.4 \mu \mathrm{g} / \mathrm{mL}$ and proves the sensitivity of the method. Robustness study of the proposed method illustrated that small and deliberate changes did not affect the results of system suitability parameters. Degradation studies confirmed that there was very less percentage $(<1 \%)$ of degradation in all the conditions and did not affect the retention time of both the drugs. All the system suitability parameters remained unaffected in the forced degradation study.

\section{Conclusion}

The current UPLC method was developed and validated for the simultaneous estimation of Bempedoic acid and Ezetimibe in tablets. The stability indicating nature of the UPLC method was established from the degradation studies as all the peaks were resolved within the limits of system suitability. The proposed method is simple, rapid, economical, accurate, precise and yet stability indicating. This UPLC method be successfully employed for routine simultaneous analysis of Bempedoic acid and Ezetimibe in pharmaceutical formulations.

\begin{abstract}
Abbreviations
LDL-C: Low density lipoprotein cholesterol; ASCVD: Atherosclerotic cardiovascular disease; hs-CRP: High-sensitivity C-reactive protein; NPC1L1: NiemannPick C1-like 1; ACL: Adenosine triphosphate citrate lyase; RP-UPLC: Reverse phase ultra-performance liquid chromatography; TUV: Tunable ultraviolet; ICH: International council for harmonization; LOD: Limit of detection; LOQ: Limit of quantification; BA: Bempedoic acid; EZ: Ezetimibe; HPLC: High-performance liquid chromatography; LC-MS: Liquid chromatography-mass spectrometry.
\end{abstract}

\section{Acknowledgements}

The authors are grateful to M/S GITAM Institute of Pharmacy, GITAM Deemed to be University, Visakhapatnam, India for providing the research facilities.

\section{Authors' contributions}

UY was experimental in performing the study and generating the required data. SG was involved in the preparation of manuscript. The authors read and approved the final manuscript.

\section{Funding}

Not applicable.

Availability of data and material

All the required data and material are available on request.

\section{Declarations}

Ethics approval and consent to participate

Not applicable.

Consent for publication

Not applicable.

\section{Competing interests}

The authors have no conflict of interest regarding the publication of this paper.

Received: 26 July 2021 Accepted: 7 October 2021

Published online: 16 October 2021

\section{References}

1. Akshaya SB, Nadya OAM, Cain CTC, Jamal R (2021) Bempedoic acid and ezetimibe for the treatment of hypercholesterolemia: a systematic review and meta-analysis of randomized phase II/III trials. Clin Drug Investig 41:19-28. https://doi.org/10.1007/s40261-020-00989-1

2. Binh APP, Thomas DD, Peter PT (2012) Ezetimibe therapy: mechanism of action and clinical update. Vasc Health Risk Manag 8:415-427. https://doi. org/10.2147NHRM.S33664

3. Ozlem B, Christie MB (2016) Bempedoic acid (ETC-1002): an investigational inhibitor of ATP citrate lyase. Curr Atheroscler Rep 18:61. https:// doi.org/10.1007/s11883-016-0611-4

4. Khemchand G, Indrajeet, (2015) Development of UV spectrophotometric method for the estimation of ezetimibe from tablet formulation. Int J Chem Sci 13:1051-1056

5. Metreyi S, Deepali VM, Mahadik M, Kadam SS, Dhaneshwar SR (2008) UV and three derivative spectrophotometric methods for determination of ezetimibe in tablet formulation. Indian J Pharm Sci 70:258-260. https:// doi.org/10.4103/0250-474X.41471

6. Narasimharaju BC, Devalarao G, Ramanjaneyulu S (2008) Spectrophotometric method for the determination of ezetimibe in pharmaceutical formulations. Biomed Pharmacol J 1:413-416

7. Kabra RP, Kadam SC, Mane VB, Kadam SS, Mamde CG (2014) Simple novel UV-spectroscopic method for estimation of ezetimibe in tablet dosage form. Am. J Pharm Health Res 2(9). 
8. Rajput SJ, Raj HA (2007) Simultaneous spectroscopic estimation of ezetimibe and simvastatin in tablet dosage forms. Indian J Pharm Sci 69:759-762. https://doi.org/10.4103/0250-474X.39429

9. Namratha S, Uma Rajeswari B, Swathi B, Arunk S, Ratnakar N (2017) UV spectrophotometric method development and validation of ezetimibe and simvastatin in bulk and pharmaceutical dosage form. Int J Pharma Chem Res 3:581-585

10. Varsha BM, Surekha B, Nita K (2011) Development of UV spectrophotometric method for the simultaneous estimation of simvastatin and ezetimibe in tablet dosage form by simultaneous equation and absorbance ratio method. Int J Pharm Tech Res 3:1459-1466

11. Seema MD, Manjusha PY (2015) First derivative UV-spectrophotometric method for simultaneous determination of simvastatin and ezetimibe in tablet dosage form. Pharm Lett 7:124-128

12. Anuradha G, Vishal SD (2010) Simultaneous UV-spectrophotometric estimation of rosuvastatin and ezetimibe in their combined dosage forms. Int J Pharm Pharm Sci 2:131-138

13. Rajput SJ, Raj HA (2009) Simultaneous estimation of ezetimibe and rosuvastatin in drug mixture by first derivative spectroscopic method. Int J Chem Sci 7:2354-2362

14. Sonawane SS, Shirkhedkar AA, Fursule RA, Surana SJ (2007) Simultaneous spectrophotometric estimation of atorvastatin calcium and ezetimibe in tablets. Indian J Pharm Sci 69:683-684. https://doi.org/10.4103/0250$474 \times .38477$

15. Manish K, Khandare MM, Kamble KG, Kamble KG (2011) UV Spectrophotometric estimation of ezetimibe and fenofibrate in bulk drug and dosage form using simultaneous equation method. Int J Chem Technol Res 3:749-754

16. Sistla R, Tata VSSK, Kashyap YV, Chandrasekar D, Diwan PV (2005) Development and validation of a reversed-phase HPLC method for the determination of ezetimibe in pharmaceutical dosage forms. J Pharm Biomed Anal 39:517-522

17. Akmar SK, Lata K, Asha T, Sumitra J, Deshpande AD (2007) Reverse phase high performance liquid chromatography method for estimation of ezetimibe in bulk and pharmaceutical formulations. Indian J Pharm Sci 69:695-697. https://doi.org/10.4103/0250-474X.38482

18. Saroj KR, Atna Bhaskar A, Jhansi D (2015) RP-HPLC method development and validation for the simultaneous estimation of atorvastatin and ezetimibe in pharmaceutical dosage form. Asian J Pharm Clin Res 8:178-181
19. Mohammed IB, Vanitha PK, Krishna MG (2013) RP-HPLC method for simultaneous estimation of rosuvastatin and ezetimibe from their combination tablet dosage form. Int J Chem Anal Sci 4:205-209

20. Siva Kumar R, Santhanakrishnan MR, Kumar PN, Venkatanarayanan R (2008) Simultaneous RP-HPLC method for estimation of ezetimibe and eimvastatin in bulk and dosage forms. Res J Pharm and Tech 1:211-214

21. Fatima HB, Ayesha BK (2020) A new validated RP-HPLC method for the analysis of bempedoic acid and ezetimibe in bulk drug samples. Int J of Pharmacy Anal Res 9:248-252

22. Hossein D, Mehrdad H (2013) A rapid and sensitive LC-MS method for determination of ezetimibe concentration in human plasma: application to a bioequivalence study. Chromatographia 76:1667-1675

23. Jung-Woo B, Chang-Ik C, Sang-Hun P, Choon-Gon J, Seok-Yong L (2012) Analytical LC-MS/MS method for ezetimibe and its application for pharmacokinetic study. J Liq Chromatogr Relat Technol 35:141-152. https:// doi.org/10.1080/10826076.2011.597065

24. El-Bagary RI, Ehab FE, Zeinab AES, Ahmed MK (2014) LC-MS-MS simultaneous determination of atorvastatin and ezetimibe in human plasma. J Chromatogr Sci 52:773-780. https://doi.org/10.1093/chromsci/bmt109

25. Abhaysingh B, Mallika S, Priyanka AS, Pranav SS (2018) Simultaneous quantitation of rosuvastatin and ezetimibe in human plasma by LC-MS/ MS: pharmacokinetic study of fixed-dose formulation and separate tablets. Biomed Chromatogr 32:e4291. https://doi.org/10.1002/bmc.4291

26. Brian JE, Karen P, Cameron B, Clay TC, Ronald S (2020) Measurement of bempedoic acid and its keto metabolite in human plasma and urine using solid phase extraction and electrospray LC-MS/MS. J Chromatogr B Analyt Technol Biomed Life Sci 1154:122291. https://doi.org/10.1016/j. jchromb.2020.122291

27. Guidelines ICH (2005) Validation of analytical procedures: text and methodology. International Council for Harmonisation, Geneva

28. ICH Harmonized Tripartite Guideline (2003) Stability testing of new drug substances and new drug products Q1A (R2); International Council for Harmonization, IFPMA, Geneva, Switzerland.

29. ICH Harmonized Tripartite Guideline (2003) Stability testing: photo stability testing of new drug substances and new drug products Q1B; International Council for Harmonization, IFPMA, Geneva, Switzerland.

\section{Publisher's Note}

Springer Nature remains neutral with regard to jurisdictional claims in published maps and institutional affiliations.

\section{Submit your manuscript to a SpringerOpen ${ }^{\circ}$ journal and benefit from:}

- Convenient online submission

- Rigorous peer review

- Open access: articles freely available online

- High visibility within the field

- Retaining the copyright to your article

Submit your next manuscript at springeropen.com 